\title{
MULHERES EGRESSAS DA EJA NO ENSINO SUPERIOR - LUTAS E CONQUISTAS
}

\section{WOMEN EGRESSED FROM EJA IN HIGHER EDUCATION - FIGHTS AND ACHIEVEMENTS}

\author{
Valdete Aparecida da Silva ${ }^{1}$ \\ Mirozete Iolanda Volpato Hanoff ${ }^{2}$
}

\begin{abstract}
RESUMO: A presente pesquisa tem como objetivo geral conhecer as trajetórias das mulheres egressas da EJA que ingressaram no Ensino Superior. Como objetivos específicos: analisar a trajetória socioeducacional e sociocultural de mulheres egressas da EJA que cursam o Ensino Superior; identificar o perfil do aluno que frequenta a EJA e conhecer as políticas pedagógicas e práticas educacionais que auxiliam no acesso e permanência das mulheres egressas da EJA no Ensino Superior. A pesquisa terá caráter qualitativo, por meio de entrevista com quatro mulheres matriculadas no Ensino Superior que tenham estudado e concluído o Ensino Médio na modalidade Ensino de Jovens e Adultos - EJA. Os resultados desta pesquisa apontam que todas as quatro entrevistadas tiveram apoio e incentivo de alguém para que o Ensino Superior não fosse somente um sonho, mas, também, se tornasse uma realidade. Foram pais, irmãs, amigas que, de alguma forma, as encorajaram a viver essa realidade.
\end{abstract}

PALAVRAS CHAVE: EJA. Mulheres. Perfil. Universidade

ASTRACT: The present research has as general purpose of knowing the trajectories of the women alumni of the EJA that joined the Higher Education. As specific objectives: to analyze the socio-educational and sociocultural trajectory of women EJA alumni who attend higher education; identify the student attending EJA profile and get to know the pedagogical policies and educational practices that assist in the access and permanence of women EJA alumni in Higher Education. The research's going to be qualitative, through an interview with four women enrolled in Higher Education who have studied and completed high school in the modality of Youth and Adult Education (EJA - Ensino de Jovens e Adultos). The results of this research indicates that all four respondents had support and encouragement from someone so that higher education was not only a dream, but also became a reality. It was parents, sisters, friends who, somehow, encouraged them to live this reality.

KEYWORDS: EJA. Women. Profile. University

\footnotetext{
${ }^{1}$ Graduada em Pedagogia pela Universidade do Extremo Sul Catarinense - Unesc.

${ }^{2}$ Graduada em Pedagogia, Especialista em Fundamentos da Educação pela Universidade do Extremo Sul Catarinense - Unesc. mvh@unesc.net

Saberes Pedagógicos, Criciúma, v. 4, n² , maio/agosto 2020.- Curso de Pedagogia- UNESC
} 


\section{INTRODUÇÃO}

A EJA (Educação de Jovens e Adultos) compõe a Educação Básica em nosso país e se constitui numa modalidade do ensino regular que atende jovens, adultos e idosos que não tiveram acesso ou não concluíram seus estudos durante o período regular previsto pelas políticas educacionais brasileira. Vários motivos tiraram e ainda continuam tirando alunos e alunas do ensino regular, dentre os quais estão: repetências em série, interrupções por motivos pessoais, falta de motivação, questões econômicas e culturais etc.

Toda trajetória gera experiências únicas e emocionantes e, ao longo de toda a vida, as experiências enriquecem o conhecimento humano, enriquecem as relações sociais. Desde que iniciei a vida acadêmica, tenho aprendido muito a respeito da educação, da didática, dos saberes, mas há algo profícuo que aprendi: as experiências do outro também me ensinam muito.

No decorrer do Curso Superior, fiz estágio em uma escola na modalidade de Jovens e Adultos e, a partir de então, surgiu o desejo de pesquisar sobre as experiências e realidades das mulheres que estudaram na EJA e obtiveram êxito para ingressar no Ensino Superior.

Dessa forma, conhecer e descrever a trajetória dessas mulheres, analisar as relações entre a subjetividade delas e os condicionantes pelos quais passaram, narrar histórias "realmente vividas" será de extrema importância para a área acadêmica e social, uma vez que, ao conhecer os anseios e as conquistas das mulheres que ingressam no Ensino Superior, daremos ênfase ao empoderamento feminino em uma sociedade marcada pela cultura machista. À vista disso, valorizar essas histórias é conhecer quais as circunstâncias adversas elas enfrentaram para chegar ao Ensino Superior.

A partir das percepções do dia a dia no Ensino Superior e levando em consideração a quantidade de pessoas egressas da EJA que frequentam o Ensino Superior, a presente pesquisa reúne, além de referências bibliográficas, o estudo de caso de quatro mulheres matriculadas na Universidade para analisar a seguinte pergunta: Quais as trajetórias de mulheres da EJA no Ensino Superior?

Partindo desse questionamento, desenvolveu-se o seguinte objetivo geral: conhecer as trajetórias das mulheres estudantes da EJA que ingressaram no Ensino Superior. Da mesma forma, descrevem-se os objetivos específicos: Analisar a trajetória socioeducacional e Saberes Pedagógicos, Criciúma, v. 4, n², maio/agosto 2020.- Curso de Pedagogia- UNESC 
sociocultural de mulheres egressas da EJA que frequentam o Ensino Superior; identificar o perfil do aluno que frequenta a EJA e conhecer as políticas pedagógicas e práticas educacionais que auxiliam no acesso e permanência das mulheres egressas da EJA no Ensino Superior.

A pesquisa terá caráter qualitativo, por meio de entrevista com quatro mulheres matriculadas no Ensino Superior que tenham estudado e concluído o Ensino Médio na modalidade Ensino de Jovens e Adultos - EJA.

O estudo foi fundamentado em diferentes teóricos, como Arroyo (2001), Cortada (2013), Freire (1997) Haddad e DiPierro (2000), bem como nas Leis e Decretos Federais que abordam o conteúdo a ser pesquisado. E, por fim, serão descritas as considerações finais e as referências bibliográficas utilizadas para a realização desta pesquisa.

\section{EJA: CONSTRUÇÃO HISTÓRICA DAS LUTAS E CONQUISTAS}

A história do direito à educação no Brasil descreve um cenário de lutas e conquistas no acesso, permanência e sucesso dos âmbitos educacionais, sobretudo na educação de jovens e adultos. No processo de redemocratização no Brasil, somente após 1945 a educação de adultos recebeu a devida importância com a universalização da educação elementar (LEITE, 2012).

Já nos anos de 1960, surgiram as propostas pedagógicas de Paulo Freire, coordenador do Plano Nacional de Alfabetização. Ele defendia que, para que possamos ter uma atuação política na sociedade em que vivemos, é preciso que os sujeitos sejam capazes de pensar criticamente sobre o mundo em que vivem (FREIRE, 1987). Em meados dos anos 1960, Paulo Freire foi exilado e seu Plano Nacional de Alfabetização foi substituído pelo MOBRAL (Movimento Brasileiro de Alfabetização). Somente a partir da segunda metade do século XX o Plano passou a ser reconhecido como "Ensino Supletivo", oportunizando aos jovens e adultos a inserção ao sistema escolar, conforme LDB 5.692/71 (BRASIL, 1971).

Essa lei estabeleceu pela primeira vez, um capítulo específico para educação de jovens e adultos, o capítulo IV, sobre o Ensino Supletivo. Embora limitasse o dever do Estado à faixa etária dos sete aos quatorze anos, reconhecia a educação de adultos um direito de cidadania. (HADDAD; DIPIERRO, 2000, p. 107). 
Em 1988, com a promulgação da Constituição Federal, o direito à educação para todos os cidadãos representou um avanço significativo para a inclusão social das classes mais pobres da sociedade brasileira.

Entretanto a Educação de Jovens e Adultos (EJA), como modalidade específica da Educação Básica, aconteceu a partir da Lei de Diretrizes e Bases da Educação 9394/96, que propõe atender pessoas em exclusão social de direitos básicos à educação, que remete à interrupção de estudos no período regular de ensino obrigatório à infância, adolescência e juventude.

Em 2000, Resolução CNE/CEB 01/00, em seu Art. 5, Parágrafo Único, regulamenta e determina que:

Como modalidade da Educação Básica, a identidade própria da Educação de Jovens e Adultos considerará as situações, os perfis dos estudantes, as faixas etárias e se pautará pelos princípios de equidade, diferenças e proporcionalidade na apropriação e contextualização das diretrizes curriculares nacionais e na posição de um modelo pedagógico próprio. (BRASIL, 2000).

Já no ano 2010, é decretada a Resolução CNE/CEB nº 3/2010, que institui as diretrizes operacionais da EJA no Brasil e altera a idade mínima para o ingresso na EJA, a partir dos 15 de idade no Ensino Fundamental e 18 anos no Ensino Médio.

Segundo Cortada (2013, p. 7):

\begin{abstract}
Definida como Educação de Jovens e Adultos, EJA é uma modalidade de Educação Básica cujo objetivo é o de favorecer oportunidades de estudo a essa parcela da sociedade que não teve acesso aos estudos na idade própria. Compreender o EJA se faz necessário, devido à sua importância no cenário educacional como instrumento de inclusão da fração da sociedade cujas oportunidades foram subtraídas por efeito da situação política, econômica, social ou cultural do país.
\end{abstract}

Nesse contexto, cabe enfatizar que a EJA tem bases legais, com projetos e propostas para o acesso, permanência e sucesso, e tem por objetivo não ser excludente, ofertando direito à educação para todos. De certa forma, essas políticas auxiliaram na redução do analfabetismo no Brasil.

Tendo a LDB 9394/1996 como lei que define e regulariza a organização da educação do país, descreve-se que a EJA tem por finalidade "desenvolver o educando, assegurar-lhe a Saberes Pedagógicos, Criciúma, v. 4, n² 2, maio/agosto 2020.- Curso de Pedagogia- UNESC 
formação comum indispensável para o exercício da cidadania e fornecer-lhe meios para progredir no trabalho e em estudos posteriores.” (BRASIL, 1996).

Ademais a LDB 9394/96 descreve ainda uma seção exclusiva, seção V, para o ensino de jovens e adultos, legitimando a utilização de recursos de ensino adequados à particularidade de cada aluno, sua realidade de vida, seu trabalho e seu contexto, a fim de que o objetivo de sua escolarização seja alcançado. A Lei define, ainda, o público destinado a EJA:

\begin{abstract}
Art. 37. A educação de jovens e adultos será destinada àqueles que não tiveram acesso ou continuidade de estudos no Ensino Fundamental e Médio na idade própria. $\S 1^{\circ} \mathrm{Os}$ sistemas de ensino assegurarão gratuitamente aos jovens e aos adultos, que não puderam efetuar os estudos na idade regular, oportunidades educacionais apropriadas, consideradas as características do alunado, seus interesses, condições de vida e de trabalho, mediante cursos e exames. $\S 2^{\circ} \mathrm{O}$ Poder Público viabilizará e estimulará o acesso e a permanência do trabalhador na escola, mediante ações integradas e complementares entre si. $\S 3^{\circ}$ A educação de jovens e adultos deverá articular-se, preferencialmente, com a educação profissional, na forma do regulamento (Incluído pela Lei $\mathrm{n}^{\mathrm{o}}$ 11.741, de 2008). (BRASIL, 1996).
\end{abstract}

Assim sendo, é possível observar que se busca uma sociedade mais justa e igualitária na educação, no que tange à escolarização de jovens e adultos, pelo menos quanto à legislação. Contudo, para Freire (1997), a sociedade tem o compromisso de transformar a realidade social e, assim, construir o futuro. Mesmo que a educação sozinha não seja capaz de transformar a sociedade, sem ela, a sociedade e sua estrutura social tampouco sofrerão alterações.

\title{
2.1 O ingresso e a permanência no Ensino Superior
}

O acesso ao Ensino Superior pode ser feito de várias formas, tendo como qualificação mínima o ensino médio. Diversas formas de ingresso são aplicadas nesse ponto, dependendo da concorrência de vagas, perfil da instituição ou preocupação pedagógica. Não há uma legislação específica que esclareça as regras de acesso, tendo como exigência única que exista uma forma de ingresso regulamentada pela instituição. A partir da LDB, a discussão quanto ao acesso à Educação Superior começou no sentido de democratizá-lo. A reflexão tinha como base as condições de igualdade de acesso e permanência na escola. 
É importante iniciar apresentando as principais formas de ingresso, para, posteriormente, esclarecer os pontos que dizem respeito à permanência do acadêmico no Ensino Superior. A tradicional forma de ingresso é o vestibular, que consiste na aplicação de uma ou várias provas de múltipla escolha e/ou provas discursivas (redação), ingressando os que obtiverem notas mais altas.

Outros modelos de ingresso usualmente utilizados são a entrevista com o candidato, a análise do histórico escolar do Ensino Médio, ou as provas com habilidades específicas. Com o cenário de crescimento do Ensino Superior no Brasil, nos últimos anos, as instituições passaram a modificar sua política de ingresso para política de acesso, pois, muitas vezes, o número de vagas ofertadas é superior à demanda na maioria das instituições privadas de ensino, como mostram os dados do censo no Ensino Superior.

A forma de ingresso que interessa, em especial, a esta pesquisa é o Exame Nacional do Ensino Médio (ENEM), que surgiu em 1998 e tem, entre outras finalidades, a intenção de organizar o acesso a instituições públicas. A lógica do ENEM ultrapassa a visão da educação como simples articulador entre o Ensino Médio e o Ensino Superior, pois estipula um novo sistema de avaliação baseado em competências e habilidades, não mais como os clássicos vestibulares voltados à reprodução de informações. Nessa lógica, o ENEM abriu um espaço de ingresso de alunos de EJA ao Ensino Superior, porque é organizado pelo Sistema de Seleção Unificada (SISU), que é um processo organizado pelo Ministério da Educação (MEC), cuja intenção é selecionar estudantes para ingressar, por meio de bolsas de estudo, no ensino privado e no ensino público (BRASIL, 2016).

A política afirma que todas as universidades federais, institutos federais de educação, ciência e tecnologia e centros federais de educação tecnológica participantes do Sisu terão vagas reservadas para estudantes que cursaram o Ensino Médio em escolas públicas, de acordo com a Lei $n^{\circ}$ 12.711/2012 (Lei de Cotas). Há instituições participantes do Sisu que disponibilizam, ainda, uma parte de suas vagas para políticas afirmativas próprias (BRASIL, 2016, p. 1).

Nesse contexto, o PROUNI surge como uma alternativa para possibilitar esse acesso de igualdade.

O objetivo do programa é conceder bolsas de estudos integrais ou parciais para estudantes de graduação, cursos sequenciais ou cursos técnicos (REIS, 2013). Conforme o Saberes Pedagógicos, Criciúma, v. 4, n², maio/agosto 2020.- Curso de Pedagogia- UNESC 
Ministério da Educação, o PROUNI se dirige aos egressos do Ensino Médio da rede pública ou particular, que possuam renda per capita de, no máximo, três salários mínimos. Tendo em vista essas condições, são concedidas bolsas conforme a classificação no Exame Nacional do Ensino Médio - ENEM (BRASIL, 2014). A bolsa integral é fornecida aos estudantes que tenham renda familiar mensal de até um salário mínimo e meio. Já a bolsa parcial, que pode ser de $25 \%$ a $50 \%$, é concedida a estudantes com renda que não ultrapasse três salários (REIS, 2013). Desde a sua criação, o PROUNI beneficiou cerca de 1.400 .000 estudantes, tendo, até 2013, sete milhões de inscritos no programa.

A Portaria Normativa ${ }^{0}$ 13, de 29 de maio de 2014, que regulamenta o processo seletivo do programa, define que podem ter acesso, dentre outras categorias, os seguintes públicos descritos no Artigo 3, incisos I a III, próprios da EJA:

\footnotetext{
I - tenha cursado o ensino médio completo em escola da rede pública;

II - tenha cursado o ensino médio completo em instituição privada, na condição de bolsista integral da respectiva instituição;

III - tenha cursado o ensino médio parcialmente em escola da rede pública e parcialmente em instituição privada, na condição de bolsista integral da respectiva instituição. (BRASIL, 2014)
}

Portanto há diversas políticas públicas e alternativas de acesso aos alunos no Ensino Superior, inclusive aos egressos da EJA.

A questão é analisar se existem ações para mantê-los estudando. Via de regra, há poucas indicações de uma preocupação, de fato com estudantes que frequentaram a modalidade EJA no Ensino Superior, a ponto de não existirem indicadores formais de desempenho das faculdades, centros universitários e universidades no que refere a esse item. Os instrumentos de avaliação de cursos de Ensino Superior, mesmo a exigência mais atualizada não dispõe de nenhum indicador sobre esse quesito da EJA.

Quando o apoio ao discente previsto/implantado contempla, de maneira excelente os programas de apoio extraclasse e psicopedagógico, de atividades de nivelamento e extracurriculares não computadas como atividades complementares e de participação em centros acadêmicos e em intercâmbios (BRASIL, 2010, p. 14).

Os programas de nivelamento são obrigatórios nas instituições de Ensino Superior, na medida em que eles precisam orientar o acadêmico para o nível mínimo de habilidades e Saberes Pedagógicos, Criciúma, v. 4, n², maio/agosto 2020.- Curso de Pedagogia- UNESC 
competências para o ensino. Sendo assim, quando o egresso da EJA ingressar no Ensino Superior, é possível oferecer apoio pedagógico para que possa sanar possíveis defasagens que possam advir da modalidade de ensino, porém, não há qualquer tipo de especificidade nesse quesito.

Outra questão considerada um desafio para a permanência dos alunos da EJA no Ensino Superior é a evasão, pois os índices são maiores do que a maioria das demais modalidades de ensino, ultrapassando a cifra média de $20 \%$ anualmente, enquanto que a evasão por titulação, ou seja, aqueles alunos que entram e não obtêm o diploma num certo número de anos, é de 46\%, em média, conforme dados divulgados pelo INEP (SILVA FILHO, 2007).

Observando cotidianamente as ações de marketing das instituições privadas, é possível perceber movimentos para a captação de novos alunos, porém são raras as ações para mantêlos. Há uma preocupação com o acesso ao Ensino Superior que não é percebida em relação à permanência dos alunos nessa modalidade de ensino.

Os motivos da evasão são diversos, desde questões financeiras até questões pedagógicas ou de afiliação estudantil, ou seja, a falta de pertencimento ao contexto acadêmico, portanto, os sujeitos egressos da EJA também fazem parte desse contexto de alto risco (BERNARDIM, 2013).

A escolarização média para o nível superior apresenta-se como um desafio permanente no contexto dos estudos educacionais, requerendo investigações que vão além da realidade dos O referencial teórico que ampliou as análises das narrativas dos interlocutores empíricos desta pesquisa será apresentado no próximo capítulo, em diálogo com as concepções de projeto de futuro, autonomia, reconhecimento social e afiliação estudantil.

\subsection{Perfil do aluno EJA e a presença da mulher no cenário educacional}

O perfil dos alunos dos programas de alfabetização e de escolarização de jovens e adultos que era de uma maioria adultos (com pessoas maduras e idosas), de origem rural, sem oportunidades escolares anteriores, passou a incluir também os “jovens de origem urbana, cuja trajetória escolar anterior foi mal sucedida" (HADDAD; DI PIERRO, 2000, p. 127). 


\section{SABERES PEDAGÓGICOS}

Revista do Curso de Graduaçâo de Pedagogia - Unesc

ISSN 2526-4559

$\mathrm{Na}$ maioria das vezes, os alunos que chegam ao EJA estão desmotivados e desencorajados pelas suas realidades de vida, com a escola regular e, às vezes, com histórico de repetência. Muitos deles sentem-se perdidos no contexto atual, principalmente em relação ao emprego e à importância do estudo para a sua vida e inserção no mercado de trabalho, conforme destaca Brunel (2004).

Nas últimas décadas, foram elaboradas significativas políticas públicas voltadas às conquistas de igualdade, desenvolvimento social e econômico das mulheres, mas, infelizmente, a realidade nem sempre foi essa. As mulheres não tinham direitos sociais como cidadãs, não tinham direito ao voto, direito de voz e, muito menos, de estar inserida em um ambiente escolar. Contudo, no século XXI, a educação das mulheres inicia-se como um poderoso mecanismo para a aquisição de igualdade, de desenvolvimento social e econômico familiar.

Para Louro (1997), na sociedade brasileira, a escola sempre foi um campo reprodutor das relações sociais, ou seja, predominantemente um espaço branco e masculino. Em vista disso, a escola, como espaço social para a formação de homens e mulheres, é um ambiente por onde passam as representações de gênero, assim:

A escola é uma caricatura da sociedade. Por ela passam, como não passam por nenhum outro lugar, limitadas por diminutivos, todas as ideias que uma sociedade quer transmitir para conservar, tudo aquilo em que se acredita ou quer que se acredite (MORENO, 1999, p. 12).

Concernente à importância da escola para uma sociedade justa e igualitária, é na Educação de Jovens e Adultos que indivíduos se permitem, especialmente as mulheres, a possibilidade de enfrentar múltiplas crises sociais, econômicas e políticas, fazendo com que não haja visibilidade sobre as diversas histórias de mulheres que foram excluídas, as que não puderam aprender a ler e a escrever na infância e na juventude pela triste história de exclusão feminina

Oliveira, em sua Dissertação de Mestrado, evidenciou que o retorno à escola "significa um marco decisivo no restabelecimento dos seus vínculos com o conhecimento escolar, libertando-os do estigma do analfabetismo e dos sentimentos de inferioridade" (OLIVEIRA, 1999, p. 37).

Saberes Pedagógicos, Criciúma, v. 4, n², maio/agosto 2020.- Curso de Pedagogia- UNESC 


\section{SABERES PEDAGÓGICOS}

Revista do Curso de Graduaçâo de Pedagogia - Unesc

ISSN 2526-4559

Todavia existem diversas mulheres que conseguiram ultrapassar a condição de exclusão e inferioridade, aliando a educação à autonomia feminina para o processo de emancipação e empoderamento feminino.

No tocante à participação das mulheres na EJA, Rosemberg (1994) defende que é necessária uma reflexão sobre as barreiras impostas às mulheres e o que impossibilita a inserção e permanência escolar, bem como a falta de atenção do poder público em relação às necessidades específicas das mulheres adultas que procuram escolarização.

Diante do exposto, é essencial que pesquisas aconteçam, principalmente sobre o tema do estudo em questão, bem como fica evidente que sua publicação contribuirá de maneira singular para que não somente as mulheres adultas conquistem a escolarização, mas façam a diferença em meio a uma sociedade culturalmente machista.

\section{METODOLOGIA, APRESENTAÇÃO E ANÁLISE DOS DADOS}

O presente estudo foi realizado a partir de pesquisa de campo do tipo exploratória, com abordagem qualitativa. Segundo Gil (1991), o objetivo principal para este tipo de pesquisa é de possibilitar a proximidade do pesquisador com o problema, tornando-o explícito e aperfeiçoando determinadas ideias ou descobertas.

A pesquisa aconteceu por meio de seleção intencional de quatro mulheres que fizeram a EJA e que, atualmente, são acadêmicas do Curso Superior de Licenciatura em Pedagogia da Universidade do Extremo Sul Catarinense-UNESC. Os critérios para a seleção dos sujeitos da pesquisa foram: ter frequentado e concluído o Ensino Médio na EJA, bem como estar cursando o ensino Superior.

A coleta de dados aconteceu por meio de entrevista narrativa: na qual "o pesquisador solicita a uma pessoa, entrevistado, que lhe conte toda ou uma parte de sua experiência vivida" (BERTAUX, 2010, p. 15). A escolha desta técnica aconteceu por acreditarmos que "a entrevista tem a vantagem de envolver uma relação pessoal entre pesquisador/sujeito, o que facilita maior esclarecimento de pontos obscuros, explorando mais a fundo outras questões. (SANTOS; SANTOS, 2010) 


\section{SABERES PEDAGÓGICOS}

Revista do Curso de Graduaçăo de Pedagogia - Unesc

ISSN 2526-4559

Antes das entrevistas serem realizadas, cada sujeito leu e assinou um Termo de Consentimento, o qual declara que as acadêmicas aceitaram participar da pesquisa, mas que não serão identificadas, sendo utilizados apenas os dados dos seus relatos.

Durante toda a realização da análise, como não poderão ser identificados os sujeitos da pesquisa, foram-lhes atribuídos nomes fictícios a partir de espécies de flores como: Rosa, Tulipa, Girassol e Azaleia. A opção por flores se dá pelo fato de que, mesmo sendo tão frágeis, as flores são responsáveis pela reprodução de novas plantas, de novas histórias, e é dessa forma que as entrevistadas podem ser definidas.

O gravador para registros das entrevistas e um roteiro de perguntas foram os instrumentos utilizados neste estudo. Dessa forma, para uma melhor compreensão do resultado da coleta, as falas foram transcritas e a análise de dados e os resultados obtidos foram agrupados em textos descritivos e serão analisados ao final das falas.

A análise das respostas iniciou com as narrativas das quatro acadêmicas entrevistadas. Em seguida, os dados foram agrupados em categorias temáticas, entre as quais, destacam-se: perfil sociocultural, perfil socioeducacional dos sujeitos da pesquisa e Caminhos percorridos da EJA à universidade.

\subsection{As mulheres que mudaram suas histórias de vida}

\subsubsection{Da máquina de costura para o banco da Universidade}

Rosa tem 38 anos e está matriculada na oitava fase do curso de Pedagogia na Universidade do Extremo Sul Catarinense. A entrevistada relata que, devido ao fato de trabalhar durante o dia e estudar à noite, o que é muito cansativo, reprovou na disciplina de matemática ainda no $8^{\circ}$ ano do Ensino Fundamental, motivo que a levou a desistir de frequentar o Ensino Regular. Com a reprovação, a escola a encaminhou para o EJA e, ao concluir o Ensino Fundamental, não prosseguiu com os estudos para frequentar o Ensino Médio.

Após alguns anos, Rosa e o esposo decidiram retornar à EJA e finalmente terminar o Ensino Médio, porque ela percebia que, tendo apenas o Ensino Fundamental, seu esposo não conseguia uma melhor oportunidade de trabalho. Assim, o desejo de mudança de profissão

Saberes Pedagógicos, Criciúma, v. 4, n², maio/agosto 2020.- Curso de Pedagogia- UNESC 


\section{SABERES PEDAGÓGICOS}

Revista do Curso de Graduaçâo de Pedagogia - Unesc

ISSN 2526-4559

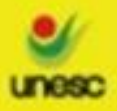

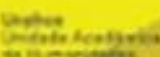

unesc

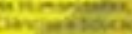

estimulou a busca pelo Ensino Superior, uma vez que, sendo costureira, sofria com dores nos membros superiores devido aos movimentos repetitivos em sua função profisssional.

Porém, ao término do Ensino Médio, não ingressou na universidade, pois "imaginava que a Unesc era apenas para quem tinha um alto poder aquisitivo". Rosa destaca que o pai foi seu maior incentivador, pois tinha o sonho de ter um filho estudando na Unesc. A partir de então, o pai de Rosa buscava na ouvidoria da Universidade uma oportunidade para que a filha ingressasse no Ensino Superior, vindo então a escrever-se para o curso de Pedagogia, concorrendo à bolsa de estudos. Rosa descreve, ainda, que após uma semana que havia feito a inscrição, foi chamada para realizar a matrícula no curso que havia escolhido.

Rosa acrescenta que as dificuldades foram muitas, por sua rotina de casa, trabalho e por ter três filhos, mas que é necessário persistir, não desistir, embora haja alguns professores que duvidem de sua capacidade: "Tem professor que pensa que não foi tu que fez aquele trabalho, que foi outra pessoa que fez [...]" não deve desistir, mas continuar buscando sempre o melhor, pois estudo é muito importante. Quanto ao futuro, a entrevistada tem expectativas de fazer especialização após a conclusão da graduação e realizar um concurso público para, assim, ingressar no magistério.

\subsubsection{Um convite de esperança: da depressão à conclusão da graduação}

Tulipa tem 36 anos de idade e encontra-se matriculada na oitava fase do curso de Pedagogia pela Universidade do Extremo Sul Catarinense. Estudou no Ensino Regular até o $6^{\circ}$ ano do Ensino Fundamental. Como os pais moravam de aluguel, faziam muitas mudanças de residência em apenas um ano e, por causa das mudanças, reprovou por duas vezes, no $1^{\circ}$ ano e, também, no $5^{\circ}$ ano. Quando estava no $6^{\circ}$ ano, após oito mudanças de endereço, nenhuma escola aceitou fazer a sua matrícula, pois já estava no mês de outubro. Foi então que houve a evasão escolar. No ano seguinte, iniciou novamente o $6^{\circ}$ ano, porém engravidou quando ainda adolescente, aos 14 anos, e abandonou definitivamente o Ensino Regular.

O ingresso na EJA aconteceu após os 21 anos de idade, convidada por uma colega de trabalho. Tulipa relata que, após dois anos frequentando a EJA, decidiu parar os estudos, porque não conseguia conciliar estudos, casa e trabalho. Contudo, anos depois, o pai e a irmã Saberes Pedagógicos, Criciúma, v. 4, n², maio/agosto 2020.- Curso de Pedagogia- UNESC 


\section{SABERES PEDAGÓGICOS}

Revista do Curso de Graduação de Pedagogia - Unesc

ISSN 2526-4559

começaram a incentivá-la a retornar à escola, pois ambos haviam frequentado a EJA e concluído o Ensino Médio. Tomada de coragem, regressou à EJA e concluiu o Ensino Médio.

O acesso ao Ensino Superior aconteceu por meio da matrícula do curso de Bacharel em Artes, no ano seguinte à conclusão do Ensino Médio pela EJA. Segundo relato de Tulipa, o que a encorajou foi a habilidade em manuseio com artesanato, embora tivesse a preocupação de que "Querendo ou não, ensino do EJA em vista do ensino regular é ensino muito fraco."

Tulipa descreve que não havia expectativas para o curso, pois, de certa forma, usava o curso como terapia para sua depressão. Mesmo encorajada, o receio de um ambiente novo e de novas interações pessoais fez com que Tulipa interrompesse a graduação por duas vezes. Ao retornar à Universidade, por ser aluna bolsista, não havia mais vagas para o curso de Artes, assim, matriculou-se no curso de Pedagogia. Tulipa relata, ainda, que tinha intenção de, após alguns semestres cursando Pedagogia, regressar ao curso de Artes, mas, em meio às amizades, à satisfação da interação social com a turma, o desejo de retomar ao curso de Artes já não mais existia.

A alegria em cursar o Ensino Superior é indescritível, pois na família são apenas primos distantes que concluíram o Ensino Superior, conforme relatou a entrevistada. O incentivo maior, de acordo com Tulipa, veio do avô, "Que sempre dizia: estuda, estuda, porque sem estudo a gente não é nada!” Na realidade, a entrevistada será a primeira pessoa da família a concluir o Ensino Superior e isso para ela é motivo de orgulho.

Tulipa acrescenta que sua perspectiva profissional é ser uma exímia professora, anseia realizar um bom trabalho profissional, ainda que haja receio do novo. Quer fazer um bom trabalho e oportunizar melhor qualidade de vida aos seus filhos.

\subsubsection{Da desistência à persistência}

Girassol tem 28 anos e, atualmente, encontra-se matriculada na oitava fase do curso de Pedagogia da Universidade do Extremo Sul Catarinense. A entrevista inicia com a narração de que, a partir da $1^{\mathrm{a}}$ série do Ensino Médio, Girassol começou a trabalhar fora de casa e, por conta disso, faltava muito à escola, o que levou à reprovação na disciplina de Língua Portuguesa. Como seria necessário estudar na $2^{\mathrm{a}}$ série no período noturno e repor a disciplina reprovada no Saberes Pedagógicos, Criciúma, v. 4, n², maio/agosto 2020.- Curso de Pedagogia- UNESC 
período da manhã, Girassol abandonou o ensino regular, porque seu principal objetivo naquele momento era trabalhar "para comprar minhas coisinhas" e não estudar. Após alguns anos, retornou ao ensino regular no período da manhã e já não trabalhava mais, porém, após algumas mudanças de período estudantil, houve novamente a evasão escolar.

Aos 18 anos, Girassol começou a trabalhar em uma agroindústria, a qual ofertava aos seus funcionários a modalidade EJA. Como o curso era da maneira que o funcionário melhor se enquadrava, ela concluiu o Ensino Médio após seis anos de estudos e, tendo a mãe professora, foi incentivada a fazer o curso de Magistério e o curso de Pedagogia concomitantemente.

Girassol relata que o ingresso no Curso Superior criou expectativas, mas, por vezes, muito medo por estar tanto tempo "longe da escola", "tinha medo porque faculdade é faculdade né, só o nome já assusta!”, tinha receio de não alcançar a nota média necessária, porém, após a primeira prova, sentiu-se realizada, porque sua nota foi muito maior do que a média exigida.

Finalmente, ter um bom emprego, trabalhar em uma boa escola, com salário justo para ter uma vida financeira melhor e ter capacidade para transmitir conhecimento aos alunos são as expectativas profissionais após a conclusão do curso de Pedagogia.

\subsubsection{Não há limites para quem tem sonhos}

Azaleia tem 50 anos e estudou no ensino regular até o $8^{\circ}$ ano do Ensino Fundamental. A entrevistada relata que a cultura familiar era terminar a $8^{\mathrm{a}}$ série ( $9^{\circ}$ ano atualmente) e, após o término, ingressar no mercado de trabalho. Foi exatamente isso que aconteceu. Casou-se ainda jovem, engravidou e, ainda assim, continuou trabalhando, mas não retornou aos estudos. Iniciou cedo a trabalhar em empresas com administração e, para Azaleia, seu salário era razoavelmente bom, o que não necessariamente faria com que desejasse retornar aos bancos da escola. Após alguns anos, divorciou-se, criou o filho e, ao casar-se novamente, ficou por determinado tempo em casa.

Aos 46 anos, quando decidiu retornar ao mercado de trabalho, Azaleia não encontrou a oportunidade que antes existia, porque, embora tivesse experiência, não havia feito graduação para ocupar as vagas ainda em aberto. O setor financeiro havia mudado e buscava não somente pessoas capacitadas, mas também graduadas na área.

Saberes Pedagógicos, Criciúma, v. 4, n², maio/agosto 2020.- Curso de Pedagogia- UNESC 


\section{SABERES PEDAGÓGICOS}

Revista do Curso de Graduaçâo de Pedagogia - Unesc

ISSN 2526-4559

Foi a partir dessa realidade que Azaleia decidiu retornar aos estudos e ingressou na EJA, com intuito de concluir o Ensino Médio. Nesse momento, sua irmã mais nova, que já havia concluído a graduação em Letras, a inscreveu no ENEM (Exame Nacional do Ensino Médio), incentivando-a a ingressar no Ensino Superior. Com o sucesso no Enem, Azaleia ingressou no Curso Superior de licenciatura em História, na modalidade $\mathrm{EaD}$, contudo não houve adaptação a essa modalidade, então Azaleia decidiu buscar a oportunidade de ingressar em outra Universidade, mas na modalidade presencial. Com êxito, ingressou no curso de Pedagogia, tendo a sua primeira oportunidade de contato com o Magistério em uma escola na modalidade EJA, auxiliando um aluno adulto com Síndrome de Down.

Azaleia descreve que o ingresso no Ensino Superior foi uma emoção indescritível. "Lembro do primeiro dia que comecei na Unesc, recebi a senha de acesso do AVA, fiquei tão emocionada que decorei a senha naquela mesma hora". A cada semestre, a cada ano que se passou no curso, a entrevistada acrescenta que seus sonhos foram renovados, que o Curso Superior mudou toda a sua vida e que suas perspectivas para o futuro são as de trabalhar na comunidade escolar com jovens e adultos, ou, ainda, preferencialmente na gestão escolar, porque seu desejo maior é fazer a diferença em nossa sociedade.

\subsection{Trajetória sociocultural das entrevistadas}

Neste bloco, buscou-se conhecer os perfis e a trajetória sociocultural das entrevistadas. Levou-se em consideração suas idades quando concluíram a EJA e quando ingressaram na universidade. Considerou-se também suas origens em relação a zona de residência (rural ou urbana), escolaridade dos pais, séries/etapas que cursaram na EJA e relações entre educação e trabalho.

Primeiramente, optou-se por conhecer os sujeitos da pesquisa antes do seu ingresso na EJA e na Educação Superior. Nesse sentido, Rosa aponta: "meu pai trabalhava como arrendatário em terras de terceiros, pois não tinha propriedade em seu nome". Devido ao fato de trabalhar durante o dia e estudar à noite, "o que é muito cansativo, reprovei na disciplina de Matemática ainda no $8^{\circ}$ ano do Ensino Fundamental, motivo que me levou a desistir de frequentar o ensino regular".

Saberes Pedagógicos, Criciúma, v. 4, n² 2, maio/agosto 2020.- Curso de Pedagogia- UNESC 


\section{SABERES PEDAGÓGICOS}

Revista do Curso de Graduaçâo de Pedagogia - Unesc

ISSN 2526-4559

Tulipa conta que: “eu reprovei por duas vezes, no $1^{\circ}$ ano e, também, no $5^{\circ}$ ano. Quando estava no $6^{\circ}$ ano, após oito mudanças de endereço, nenhuma escola aceitou fazer a minha matrícula, pois já estava no mês de outubro".

Constatou-se que a idade de conclusão da educação básica das mulheres entrevistadas varia entre 21 a 46 anos. Idade que atende às Diretrizes Operacionais para a Educação de Jovens e Adultos: “Art. $6^{\circ}$ Observado o disposto no artigo 4", inciso VII, da Lei $n^{\circ}$ 9.394/96, a idade mínima para matrícula em cursos de EJA de Ensino Médio e inscrição e realização de exames de conclusão de EJA do Ensino Médio é 18 (dezoito) anos completos” (BRASIL, 2010, p. 2).

Outro dado que chama atenção é que duas das entrevistadas vieram da zona rural para o centro da cidade, assim, puderam frequentar a EJA. Rosa narrou que estudava em uma escola multisseriada, situada na zona rural, onde ficou até o término do $4^{\circ}$ ano, pois era o que tinha lá no interior, na roça.

A volta à escola se ocorreu por diversos motivos. Esse retorno exigiu quebra de barreira e paradigma, já que essas mulheres em algum momento abandonaram a educação formal por motivos já citados e que posteriormente tiveram que ser superados para garantia do retorno. $\mathrm{O}$ retorno à escola "significa um marco decisivo no restabelecimento dos seus vínculos com o conhecimento escolar, libertando-os do estigma do analfabetismo e dos sentimentos de inferioridade" (OLIVEIRA. 1999. p. 37).

Outro traço do perfil sociocultural dos sujeitos da pesquisa que chama atenção está na constatação de que os pais da maioria delas possuíam baixo nível de escolaridade quando essas cursaram a EJA: "Ensino fundamental incompleto, tanto a mãe quanto o pai até a $4^{\circ}$ série" (ROSA); “O meu pai terminou o $2^{\circ}$ grau e a minha mãe estudou até a $3^{\circ}$ série do Ensino Fundamental" (TULIPA); "Eles não estudaram na EJA, minha mãe é professora e meu pai estudou até a $6^{\mathrm{a}}$ série, eu acho" (GIRASSOL).

Oliveira (1999, p. 59) aponta que o sujeito da EJA, comumente, é "filho de trabalhadores rurais não qualificados e com baixo nível de instrução escolar". A partir dessa informação, deduz-se que o histórico socioeducacional dos pais desses sujeitos reflete diretamente em sua formação.

Quando perguntamos sobre as séries/etapas que cursaram na EJA, obteve-se os seguintes dados: " $8^{\circ}, 1^{\circ}, 2^{\circ}$ e $3^{\circ}$ ano, todo Ensino Médio eu cursei na EJA" (ROSA); "Eu

Saberes Pedagógicos, Criciúma, v. 4, n² 2, maio/agosto 2020.- Curso de Pedagogia- UNESC 


\section{SABERES PEDAGÓGICOS}

Revista do Curso de Graduaçâo de Pedagogia - Unesc

ISSN 2526-4559

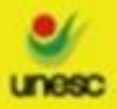

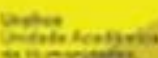

unose

ingressei na EJA e conclui meu Ensino Médio em dois anos" (GIRASSOL); "Eu fiz a 6 ${ }^{\mathrm{a}}, 7^{\mathrm{a}}$ e a $8^{\mathrm{a}}$ e fiz todo Ensino Médio" (TULIPA); "Eu fiz a 1 a série do Ensino Médio, em seguida, fiz a prova do ENEM e passei, concluí o Ensino Médio com esta aprovação" (AZALEIA).

Percebeu-se que as mulheres entrevistadas tiveram uma passagem, de certa forma, rápida pela EJA, preenchendo lacunas deixadas para trás em idade dita como regular.

Conversamos com as entrevistadas sobre quais atividades laborais exerceram concomitante à EJA. Além disso, investigou-se a razão pela qual trabalhavam. Obteve-se os seguintes registros: "Eu trabalhava como costureira numa fábrica [...] era necessário, porque só com o salário do meu marido não dava para viver, muitas vezes, minha mãe tinha que me ajudar com as comidas" (ROSA); "Na época, eu trabalhava em loja de balconista [...] trabalhei, estudei, criei meu filho, desisti da escola, voltei para terminar o ensino médio" (TULIPA); "Eu trabalhava em uma agroindústria e estudava lá" (GIRASSOL).

A partir do relato dos sujeitos da pesquisa, percebe-se que suas histórias se enquadram em um contexto da EJA de mulheres que: "lutam pela sua sobrevivência e a de seus filhos, [...] ou mesmo de busca por melhores condições de vida" (MARCARINI; MÉNDEZ, 2014, p. 335).

Nesse sentido, as mulheres que estudam na EJA, em sua maioria, já estão inseridas no mercado de trabalho e precisam conciliar emprego e estudos, na busca por qualificação profissional que implique em melhorias para si e seus dependentes.

\subsection{Trajetória socioeducacional das entrevistadas}

Para a elaboração do perfil socioeducacional, utilizaram-se os seguintes eixos orientadores: itinerário educacional na EJA; oferta da educação e o papel do Estado; e perspectiva de futuro quando cursava a EJA.

Iniciamos perguntando quais os motivos que levaram as quatro mulheres, sujeitos da pesquisa, a ingressar na EJA: "Para conseguir retornar ao mercado de trabalho mais rápido" (AZALEIA); “A EJA era à noite, menos tempo, assim, eu podia trabalhar de dia e estudar à noite" (ROSA); "Porque pude estudar na empresa, aí facilitou minha vida, não precisava sair de casa à noite" (GIRASSOL); "Incentivada pelo meu pai e minha irmã” (TULIPA). 
Percebe-se um motivo comum que as levou a cursar a EJA: a agilidade na conclusão das séries/etapas que não puderam cursar durante a infância e adolescência. Todavia as entrelinhas das narrativas revelam uma das faces da exclusão e discriminação existente em nossa sociedade, uma vez que a educação escolar enquanto direito foi-lhes negada desde sua infância, por falta de escolas que ofertassem educação escolar pública de qualidade. Essa situação fica evidente no registro a seguir:

"Estudava em uma escola multisseriada situada na zona rural, lá tinha até o $4^{\circ}$ ano só". E acrescentou: "tinha apenas uma sala de aula, estudávamos as quatro séries juntas, não tinha biblioteca, TV, material para pesquisa, nada" (ROSA).

Quando abordadas sobre o papel do Estado/município na educação pública:

Eu acho que o Estado e o município deveriam investir mais na EJA, tanto na questão de colocar mais professores especializados em trabalhar nesta modalidade, quanto na divulgação e na oferta. Na época, eram poucas as escolas que eu estudava e hoje reduziu mais ainda. Não tinha muitas escolas, tinha que andar um bom pedaço para chegar à escola, e era muito difícil! (ROSA).

Outra delas ressalta:

Na minha opinião, o que o Estado está fazendo é apenas ofertar as vagas, mas não garante a permanência do educando, por exemplo, os professores não motivam os alunos a estudaram, a irem a diante, não investe em materiais e metodologias adequadas para esta modalidade (TULIPA).

Nesse contexto, percebe-se a realidade de descaso na qualidade da educação oferecida, na quantidade de escolas insuficientes, principalmente em se tratando de educandos que já são adultos, bem como a falta de políticas e práticas pedagógicas de permanência do educando da EJA.

Para compor o presente perfil, tornou-se relevante obter informações sobre suas perspectivas de futuro enquanto cursaram a EJA: "Eu sonhava para o meu futuro, primeiramente um emprego melhor, que me proporcionasse uma renda maior, para que eu pudesse ter uma melhor qualidade de vida, não somente para mim, mas para minha família também" (ROSA). Este era o sonho de Rosa, o desejo de mudança de profissão foi o que a 
estimulou na busca pelo Ensino Superior, uma vez que, sendo costureira, sofria com dores nos membros superiores devido aos movimentos repetitivos em sua função profisssional.

"Quando entrei na EJA, já tinha um papel bem definido do que eu realmente queria, era o Ensino Superior” (AZALEIA); “A alegria em cursar o Ensino Superior é indescritível, pois na família são apenas primos distantes que concluíram o Ensino Superior” (TULIPA).

Essas narrativas demonstram que, mesmo com todos os problemas que cercam a modalidade, a EJA tem contribuído para a superação da exclusão social, oportunizando que seus sujeitos-educandos deem continuidade aos estudos e à realização de sonhos interrompidos.

A respeito disso, Bernardim (2013, p. 215) escreve que:

\begin{abstract}
Na modalidade EJA permanece forte a percepção de que a educação pode contribuir não só para a melhoria das condições de trabalho e renda, como para a obtenção de emprego. Essa perspectiva também tem se ampliado entre aqueles que, tendo concluído o Ensino Médio há mais tempo, percebem o nível superior como importante para melhorar sua condição de inserção socioeconômica. Assim, almejaram chegar à educação superior com a perspectiva de melhorar suas condições materiais de vida, passando a valorizar cada vez mais a universidade como meio de ascensão e inclusão social.
\end{abstract}

Assim, percebe-se que as mulheres, sujeitos da pesquisa, sonharam chegar à educação superior com a perspectiva de melhorar suas condições de vida, passando a valorizar cada vez mais a universidade como meio de inclusão e ascensão social.

\title{
3.4 Caminhos percorridos da EJA à universidade
}

Duas perguntas contribuíram para a construção desse bloco: $\left(1^{\mathrm{a}}\right)$ Conte como foi para você conquistar uma vaga na educação superior; $\left(2^{\mathrm{a}}\right)$ Narre sua perspectiva de futuro quando concluir o curso de graduação.

No primeiro bloco, buscou-se compreender o significado que as mulheres universitárias egressas da EJA atribuíram à conquista de uma vaga na educação superior. A respeito disso, as entrevistadas narram o sentimento que tiveram ao saber que haviam conquistado uma vaga na universidade pública: 


\section{SABERES PEDAGÓGICOS}

Revista do Curso de Graduaçăo de Pedagogia - Unesc

ISSN 2526-4559

Foi emocionante! Porque eu estava há quase 10 anos sem estudar, quando vi que o resultado do ENEM tinha sido muito bom, e minha redação tinha sido excelente, para quem estava tanto tempo sem estudar, foi maravilhoso! Foi uma emoção indescritível. Lembro do primeiro dia que comecei na Unesc, recebi a senha de acesso do AVA, fiquei tão emocionada que decorei a senha naquela mesma hora! (AZALEIA).

O pai de Rosa buscava na ouvidoria da Universidade uma oportunidade para que a filha ingressasse no Ensino Superior, vindo então a escrever-se para o curso de Pedagogia, concorrendo à bolsa de estudos. Rosa descreve, ainda, que uma semana após fazer a inscrição, foi chamada para realizar a matrícula no curso que havia escolhido.

Ambas as narrativas expressam, de forma muito marcante, o sentimento de realização. As mulheres tinham seus sonhos quase perdidos (mas não esquecidos), como o de fazer um curso superior e, com a conquista de uma vaga na universidade, nasce a esperança de "mudar de vida".

Diante disso, Freire (1992, p. 91) afirma que "não há mudança sem sonho, como não há sonho sem esperança". Percebe-se, assim, que essas mulheres passaram a acreditar e a valorizar cada vez mais a universidade, como meio para sua inclusão social.

No segundo bloco buscou-se conhecer a perspectiva de futuro das acadêmicas após conclusão da graduação. Percebe-se a quase unanimidade em relação a continuar estudando e por em prática o que aprenderem na academia.

Expectativas de fazer especialização após a conclusão da graduação e realizar um concurso público para, assim, ingressar no Magistério. (ROSA)

Suas perspectivas para o futuro são as, poder continuar a estudar, de trabalhar na comunidade escolar com jovens e adultos, ou, ainda, preferencialmente, na gestão escolar, porque seu desejo maior é fazer a diferença em nossa sociedade. (AZALEIA)

É ser uma exímia professora, anseia realizar um bom trabalho profissional. (TULIPA)

Compreende-se que as entrevistadas estão escrevendo e reescrevendo suas histórias de vida. O que iniciou com um sonho, sustentou-se de esperança, confiança e coragem para materializar-se, pois “[...] não há amanhã sem projeto, sem sonho, sem utopia, sem esperança, sem o trabalho de criação e desenvolvimento de possibilidades que viabilizem sua concretização" (FREIRE, 2001, p. 86).

Saberes Pedagógicos, Criciúma, v. 4, n² 2, maio/agosto 2020.- Curso de Pedagogia- UNESC 


\section{SABERES PEDAGÓGICOS}

Revista do Curso de Graduaçâo de Pedagogia - Unesc

ISSN $2526-4559$

Assim como um dia a possibilidade de ingressar no ensino superior era apenas um sonho para essas mulheres, certamente existe um universo de alunos da EJA que compartilham desse mesmo sonho.

\section{CONCLUSÃO}

Este estudo é resultado de um sonho, de perspectivas alcançadas com o objetivo de conhecer as trajetórias das mulheres egressas da EJA matriculadas no Ensino Superior, bem como analisar o perfil sociocultural e educacional das mulheres egressas na EJA. Os dados coletados a partir das entrevistas nos mostram que as mulheres egressas da EJA são trabalhadoras, mães, mulheres que enfrentaram diversos obstáculos, tais como físico, emocional e pessoal para que o curso em uma universidade fosse realidade.

Os dados coletados a partir das entrevistas nos mostram que, das quatro entrevistadas, apenas uma não teve filhos durante a evasão escolar. Outro fator relevante quanto ao perfil socioeconômico foi a falta de recursos financeiros das famílias, bem como o desprezo do Estado referente às políticas públicas contra a evasão escolar de adolescentes, ou seja, podemos perceber que a falta de políticas públicas do Estado para evitar a evasão escolar é algo que se desencadeia há décadas.

Podemos destacar que, atualmente, existem poucas campanhas tanto nacionais quanto estaduais de incentivo ao acesso e permanência dos alunos nas escolas, sobretudo dos alunos da EJA, já que uma entrevistada descreveu que jamais nenhum professor da EJA a incentivou, ou falou algo sobre o ingresso em um Curso Superior após a conclusão do Ensino Médio na modalidade Jovens e Adultos.

Os resultados desta pesquisa apontam que todas as quatro entrevistadas tiveram apoio e incentivo de alguém para que o Ensino Superior não fosse somente um sonho, mas, também, se tornasse real. Foram pais, irmãs, amigas que, de alguma forma, as encorajaram a viver essa realidade.

Diante das histórias narradas, foi possível compreender que o acesso ao Ensino Superior é mais que apenas a expectativa de um diploma, é também a possibilidade para novas conquistas, 
é inclusão social, é oportunidade de interação social, de novas histórias e, principalmente, novos começos e novas perspectivas de vida.

Considera-se, portanto, que as quatro mulheres entrevistadas fazem parte de um paradigma social que, embora venha lentamente se transformando nos últimos anos, representa a superação e a realização profissional feminina. Apesar dos mais diversos obstáculos, tanto sociais quanto econômicos, elas superaram a exclusão das mulheres no núcleo educacional, quando se refere à classe média baixa em nosso país.

Contudo é fundamental registrar a necessidade da continuidade de mais pesquisas a respeito do perfil das mulheres que ingressam no Ensino Superior, assim como mais pesquisas que tratem das trajetórias dos alunos da EJA. As pesquisas são de extrema importância para a construção de uma sociedade mais justa e democrática. Cabe, ainda, lembrar que não apenas pesquisar, mas também publicar essas pesquisas é de suma importância, pois conhecimento compartilhado é conhecimento que traz transformação.

\section{REFERÊNCIAS}

ARROYO, Miguel. A Educação de Jovens e Adultos em tempos de exclusão. Alfabetização e Cidadania: Revista de Educação de Jovens e Adultos, São Paulo: n. 11, p. 9-20, abr. 2001.

BERNARDIM, Márcio Luiz. Educação e Trabalho na perspectiva de egressos do ensino médio e estudantes universitários. In: Nuances: estudos sobre educação, Presidente Prudente, v. 24, n. 1, p. 200-217, jan./abr. 2013. Disponível.

BERTAUX, Daniel. Narrativas de vida: a pesquisa e seus métodos. Natal-RN: EDUFRN; São Paulo: Paulus, 2010.

BRASIL. Câmara dos Deputados. Lei no 5.692, de 11 de agosto de 1971. Fixa Diretrizes e Bases para o ensino de $1^{\circ}$ e $2^{\circ}$ graus, e dá outras providências. Diário Oficial da União: seção 1, Brasília, DF, p. 6.377, 18 ago. 1971.

BRASIL. Ministério da Educação. Conselho Nacional de Educação. Parecer CNE/CEB no 11/2000. Diretrizes Curriculares Nacionais para a Educação de Jovens e Adultos. Diário Oficial da União: seção 1e, Brasília, DF, p. 15, 9 jun. 2000.

BRASIL. Ministério da Educação. Conselho Nacional de Educação. Resolução CNE/CEB no 1/2000. Diretrizes Curriculares para a Educação de Jovens e Adultos. Diário Oficial da União: seção 1, Brasília, DF, p. 18, 19 jul. 2000.

Saberes Pedagógicos, Criciúma, v. 4, n², maio/agosto 2020.- Curso de Pedagogia- UNESC 


\section{SABERES PEDAGÓGICOS}

Revista do Curso de Graduaçâo de Pedagogia - Unesc

ISSN 2526-4559

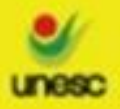

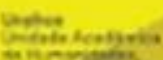

BRASIL. Ministério da Educação. Portaria Normativa n ${ }^{0}$ 13, de 29 de maio de 2014.

Regulamenta o processo seletivo do Programa Universidade para Todos, referente ao segundo semestre de 2014. Diário Oficial da União: seção 1, n. 102, Brasília, DF, 30 maio 2014.

BRASIL. Ministério da Educação. Resolução CNE/CEB n 3, de 15 de junho de 2010. Institui Diretrizes Operacionais para a Educação de Jovens e Adultos nos aspectos relativos à duração dos cursos e idade mínima para ingresso nos cursos de EJA; idade mínima e certificação nos exames de EJA; e Educação de Jovens e Adultos desenvolvida por meio da Educação a Distância. Diário Oficial da União, Brasília, DF, 7 abr. 2010.

BRASIL. Presidência da República. Lei no 12.711, de 29 de agosto de 2012. Dispõe sobre o ingresso nas universidades federais e nas instituições federais de ensino técnico de nível médio e dá outras providências. Diário Oficial da União, Brasília, DF, 30 ago. 2012.

BRASIL. Presidência da República. Lei no 9.394, de 20 de dezembro de 1996. Estabelece as diretrizes e bases da educação nacional. Diário Oficial da União, Brasília, DF, 23 dez. 1996. Disponível em: http://bit.ly/2N2IsSv. Acesso em: 11 maio 2019.

BRUNEL, Carmen. Jovens cada vez mais jovens na educação de jovens e adultos. Porto Alegre: Mediação, 2004.

CORTADA, Silvana (org.). EJA: Educação de jovens e adultos e seus diferentes contextos. Jundiaí, SP: Paco, 2013. 200 p. (Pedagogia de A a Z; v. 12).

FREIRE, Paulo. Desafios da educação de adultos frente à nova reestruturação tecnológica. Seminário Internacional Educação e Escolarização de Jovens e Adultos. Brasília: MEC, 1997.

FREIRE, Paulo. Pedagogia da Esperança: um reencontro com a pedagogia do oprimido. Rio de Janeiro: Paz e Terra, 1992.

FREIRE, Paulo. Pedagogia do oprimido. 17. ed. Rio de Janeiro: Paz e Terra, 1987.

FREIRE, Paulo. Pedagogia dos Sonhos Possíveis. São Paulo: UNESP, 2001.

GIL, Antônio Carlos. Como elaborar projetos de pesquisa. São Paulo: Atlas, 1991.

HADDAD, Sérgio; DI PIERRO, Maria Clara. Escolarização de jovens e adultos. Revista Brasileira de Educação, n. 14, p. 108-130, maio/jun/jul./ago. 2000.

LEITE, Sandra Fernandes. Políticas Públicas para a Educação de Jovens e Adultos no período 2000-2010. Portal da Educação. São Paulo, 2012. Disponível em: http://bit.ly/2o8z5Z2. Acesso em: 11 maio 2019. 
LOURO, Guacira Lopes. Gênero, sexualidade e educação: uma perspectiva pós estruturalista. Petrópolis, RJ: Vozes, 1997.

MARCARINI, Camila Tomazzoni; MÉNDEZ, Natalia Pietra. Gênero, geração e patriarcado: a EJA na construção da resistência e autonomia das mulheres. In: STECANELA, Nilda et al. (orgs.). Ler e escrever o mundo: a EJA no contexto da educação contemporânea. Caxias do Sul, RS: EDUCS, 2014.

MORENO, Montserrat. Como se ensina a ser menina: o sexismo na escola. São Paulo: Moderna; Campinas, SP: UNICAMP, 1999.

MOROZ, Melania; GIANFALDONI, Monica Helena T. A. O processo de pesquisa: iniciação. 2. ed. São Paulo: Liber, 2006.

OLIVEIRA, Marta Kohl. Jovens e adultos como sujeitos de conhecimento e de aprendizagem. In: Revista Brasileira de Educação, v. 1, n. 12, p. 59-73, set./out./nov./dez. 1999. Disponível em: http://bit.ly/37yKMtY. Acesso em: 31 out. 2019.

REIS, Júlio Adriano Ferreira dos. Relevância e história: uma análise do programa universidade para todos do governo brasileiro. Revista Cesumar: Ciências Humanas e Sociais Aplicadas, v. 18, n. 2, p. 337-351, jul./dez. 2013.

ROSEMBERG, Fluvia. A educação de mulheres jovens e adultas no Brasil. São Paulo: Global, 1994.

SANTOS, Maria de Fatima Ribeiro dos; SANTOS, Saulo Ribeiro dos. Metodologia da pesquisa em educação. São Luiz: Uemanet, 2010. 67 p. Disponível em:

http://bit.ly/322a6EK. Acesso em: 27 jun. 2019.

SILVA FILHO, Roberto Leal Lobo et al. A evasão no ensino superior brasileiro. Cadernos de Pesquisa, v. 37, n. 132, p. $641-659,2007$. 